\title{
EVIDENTSIAALID: KAS USKUDA VÕI MITTE? TEABE VORMI MÕJU EESTI KOOLIEELIKUTE KÄITUMISELE
}

\author{
ANNE TAMM, REILI ARGUS, \\ KADRI SUURMÄE
}

Ülevaade. Artikli eesmärk on selgitada kommunikatsioonis kasutatavate grammatikavahendite mõju laste käitumisele. Artiklis antakse esmane ülevaade psühholingvistilise katse abil saadud andmetest evidentsiaalsele teabele reageerimise kohta. Katses uurisime, kas grammatika mõjutab nelja-kuueaastaste lasteaialaste käitumist uute esemete ja omaduste avastamisel, kuidas grammatilised keelevahendid mõjutavad teabe kategoriseerimist, ja mõõtsime seda järgneva tegevuse kaudu. Katse käigus anti lastele ühe uue eseme eksemplari omaduste kohta kahel kujul informatsiooni: algtingimuse puhul indikatiivis lihtlausega (42 katset) ja evidentsiaalitingimuse puhul kaudse kõneviisi markerit (-vat) kasutades (43 katset). 85 lapsega tehtud katse tulemustest võib järeldada, et evidentsiaalide kasutamine laste üldistusprotsesse ei pärssinud ehk teisisõnu: vahendatud teave ei tekitanud lastes tunnet, et see informatsioon on oluliselt vähem üldistamist väärt. Nelja-aastaste lastega tehtud katsete tulemustest võib järeldada, et lapsele suunatud keeles kasutatud evidentsiaalid tekitavad lastes uute esemete omaduste või uue grammatika tähenduse vastu huvi. Arvame, et uue grammatika kasutamine tekitab lastes soovi teada saada, mis mõju sellel on. Kuueaastaste puhul evidentsiaalidega tehtud katsete tulemused suurenenud huvi enam ei näidanud ja olid sarnased algtingimuse tulemustega.

Võtmesõnad: evidentsiaalsus, õppimine, lastekeel, hoidjakeel, eksperimentaalsed meetodid

\section{Sissejuhatuseks}

Artikli eesmärk on vaadelda, kas grammatiline info mõjutab eesti neljaja kuueaastastel lastel ümbritseva tajumist ja õppimist, täpsemalt seda, kas grammatilised vahendid, nagu indikatiiv ja evidentsiaalsus (kaudne kõneviis), võivad mõjutada õppimisprotsessi ja kategoriseerimist erinevalt ning kas nende tajumine on nelja- ja kuueaastastel erisugune. 
Evidentsiaalsus on keeleliselt vormistatud viide info allikale ning evidentsiaalid seega grammatilised markerid, mis näitavad, kas öeldu kohta on olemas tõendus ja milline see on. Evidentsiaalsus võib olla otsene, st et kõneleja räägib millestki, mille otsene tunnistaja ta on olnud, või vahendav, kaudne või järelduslik, st et kõneleja vahendab kelleltki teiselt saadud infot või järeldab sellest infost midagi (vt nt Aikhenvald 2004: 3; Erelt 2013: 121).

Evidentsiaalsust väljendatakse paljudes keeltes ning selleks on kasutusel mitmesuguseid võimalusi, nii grammatilisi kui ka leksikaalseid (vt nt Aikhenvald 2004: 10). Mitte kõikides keeltes ei ole evidentsiaalsuse kategooria grammatiliselt väljendatud, samuti ei ole suguslaskeeltest läänemeresoome keelteski (peale liivi keele) eesti keele evidentsiaalsuse sarnaseid ehk siis grammatilisi vahendeid, nt kaudse kõneviisi vasteid (Kehayov 2004: 812). Otsese evidentsiaalsuse väljendamiseks ei ole eesti keeles grammatikavahendeid, kaudse evidentsiaalsuse väljendamiseks saab kasutada leksikaalsete vahendite ja evidentsiaalsusstrateegiate kõrval ka grammatilisi (Kehayov 2004: 829; Erelt 2013: 121). Nii saab kaudse kõneviisi vormiga märkida väite vahendatust näiteks lauses Sinine lasteaed olevat parem, kus vat-lõpu abil annab kõneleja märku, et info allikas ei ole tema ise ja et ta ei saa ise selle väite tõesuses täiesti kindel olla. Eesti evidentsiaal väljendab nii kaudsust (seda, et info pärineb kelleltki teiselt) kui ka episteemilist modaalsust (seda, et rääkija ei ole väites täielikult kindel) (vt nt Tamm 2009: 376-379; Erelt 2013: 126).

Eksperimentaalse andmestiku põhjal on selgunud, et evidentsiaale kasutatakse kognitiivse dissonantsi puhul kui strateegilist suhtlusvahendit (Arguse jt ettekanne ${ }^{1}$; Kütt jt 2014). Situatsioonid, kus kognitiivne dissonants esineb, on näiteks need, kus on konflikt kõneleja enda sotsiaalsete huvide (kõneleja soovib olla inimene, keda saab teabe allikana usaldada) või enesehinnagu (kõneleja soovib olla enese silmis aus) ja teisalt mingit tüüpi materiaalsete huvide vahel. Kui näiteks tuleb suhtlejail mingite ressursside (lapse lasteaiakoht vms) pärast võistelda, pakuvad evidentsiaalid (kaudses kõneviisis või pidama-verbi konstruktsioone sisaldavad laused) võimaluse küll rääkida tõtt, kuid hägustada teavet ja peita info allikas. Situatsioonides, kus millegi pärast võistelda ei tule, kasutatakse evident-

1 Reili Argus, Airi Kapanen, Andra Kütt, Sirli Parm, Kadri Suurmäe, Anne Tamm, Evidentsiaalidel on täiskasvanute ja laste seas erinev funktsioon. Ettekanne konverentsil „Teoreetiline keeleteadus Eestis IV” 17. detsembril 2013 Tartus. 
siaale tunduvalt vähem. Näiteks võib tuua katse (Giardini jt ilmumas), kuidas jagavad eesti ja türgi keele kõnelejad infot eri tüüpi situatsioonides. Situatsioonis, kus tuli oma tuttavaga lasteaiakoha pärast võistelda ehk kus mängus olid mitmesugused, nii sotsiaalpsühholoogilised kui ka materiaalsed huvid, kasutasid katsealused tihti evidentsiaale. Seega pakuvad evidentsiaalid võimaluse vaadelda lähemalt sotsiaalse taju (ingl social cognition) ja keele suhteid. Nende suhete arenemise algetapi kohta on võrdlemisi vähe teada.

Kokkuvõtvalt võib öelda, et evidentsiaalsus on kategooria, mille puhul tuleb arvestada, et kategooria episteemiline olemus hõlmab kõnelejat ja kuulajat erinevalt. Evidentsiaalsus on selle poolest teistsuguse tähendusstruktuuriga grammatiline kategooria kui näiteks mitmus, ta on seotud tihedamalt kultuuritavade ja pragmaatikaga. Kui mitmuse kasutamisega tahab kõneleja väljendada, et midagi on rohkem kui üks ja see on midagi loendatavat, siis kuulaja saab sellest ka nii aru. Evidentsiaalide puhul kõneleja ja kuulaja teadvus teabe edasiandmise järel ideaalpildis kattuvad, aga üldjuhtudel ei ole kattumine täielik. Viimasel juhul esitab kõneleja teavet nii, et see oleks kuulaja jaoks optimaalselt informatiivne, aga vastaks ka ta enda suhtluseesmärkidele. Mitmuse ja ainsuse kasutamise puhul on suhtluseesmärgid tagaplaanil. Evidentsiaalide puhul tõlgendab kuulaja kuuldut oma seisukohast, aga üritab ka mõistatada, miks kõneleja mingit kindlat vormi kasutab. Kõneleja üritab omalt poolt kuulajale teadaolevat mõistatada ja selle järgi oma öeldut vormida. Seega ei ole öeldu evidentsiaalide puhul selgesti tajutav, vastupidi näiteks mitmusele, ning kõneleja ja kuulaja tähendus (lausega seostatud semantika) ei pruugi alati ühte langeda (Hendriks, Hoop 2001: 1-32). Evidentsiaalide puhul võib kõneleja soovida end teabest distantseerida (nt Eestlane olevat laisk, aga mina sellele nii julgelt alla ei kirjutaks).

Kuna evidentsiaalsusega antakse teada varasemas kõnesituatsioonis kuuldud informatsiooni, mida kõneleja ei ole piisavalt omaks võtnud, et enda seisukohana esitada, oleneb selle kategooria mõistmine palju kuulaja kognitiivsest arengust. On väidetud, et lapsed hakkavad kolmeaastaselt pilgu, näoilme ja hääletooni alusel mõistma ümbritsevate käitumist. Teiste inimeste mõtete ja kavatsuste mõistmine hakkab lastel arenema koolieelses eas, kusjuures rohkem varjatud kavatsuste mõistmiseks olulised sotsiaalsed oskused kujunevad välja alles 7-12 aasta vanuses (Kolk jt 2010: 726). Seetõttu võib väita, et evidentsiaalsuse omandamine peegeldab sotsiaal- 
psühholoogilist arengut. Evidentsiaalsuse väljendusvahenditega annab kõneleja märku, et teadmine võib olla pärit mitmest allikast. See teeb öeldu tahes tahtmata lünklikuks, sest evidentsiaal sisaldab enne kõnehetke toimunud teabe edastamist ühelt isikult teisele - tegevust, millest saab midagi järeldada või mille tunnistajaks (kas siis visuaalsel või muul moel) kõneleja oli. Seetõttu eeldab evidentsiaal kuuldud lausungi analüüsimist ning arusaama, et mitmest allikast pärit info peaks viima üldistusele, see protsess toetub aga kuulaja kognitiivsele arengule.

Siinse uuringu eesmärk oligi teada saada, kas eelnimetatud kaalutlustel põhinev hüpotees teabe kategoriseerimise kohta peab paika ning kuidas need protsessid tekivad ja arenevad. Täpsemalt vaatlesime, kas nelja- ja kuueaastased lapsed tõlgendavad evidentsiaali eesti keeles filtrina, mis näitab, et kuna teave tuleb kelleltki teiselt ega pruugi tõene olla, siis on see seetõttu vähem üldistatav ning takistab saadud teabe üldkehtivate (geneeriliste), õppimisele-omandamisele kuuluvate teadmistena kategoriseerimist. Sel eesmärgil on uuringus rakendatud Lucas Butleri ja Ellen Markmani (2012) plikititesti, mida nad kasutasid osutava (ostensiivse) suhtlemise uurimisel. Osutavaks ehk ostensiivseks nimetatakse suhtlemist siis, kui suhtlemise eesmärk on anda edasi teavet „See, mida ma nüüd ütlen või teen, on oluline, pane tähele". Butleri ja Markmani katse näitas, et osutava-pedagoogilise, ent mittekeelelise info edastamisel üldistasid lapsed rohkem kui juhuslikult vaatluse teel omandatud info puhul.

Katses antakse lastele näha uut mänguasja nimega plikit (ingl blicket), millele omistatakse keelelisel teel mingi omadus, ning uuritakse teabe kategoriseerimist selle kaudu, kuidas laps ühe eksemplari kohta saadud teavet teistele eksemplaridele laiendab ja rakendab. Täpsem uurimisküsimus on: kas lapsed reageerivad otsesele ja vahendatud informatsioonile (ehk evidentsiaalidele) erinevalt? Kuna türgi keelt omandavate lastega tehtud katsete (Tamme jt ettekanne ${ }^{2}$ ) põhjal on teada, et eri eagruppide lapsed reageerisid evidentsiaalidega esitatud infole mõnevõrra teisiti kui indikatiivis ja geneerikutega esitatud infole, võib oletada, et sarnased tulemused võib saada ka eesti keelt omandavate laste katsetel. Mõlemal puhul vaadeldi, kuivõrd visad on lapsed info paikapidavust katsetama. Samas tuleb aga

2 Anne Tamm, Ayhan Aksu-Koç, Leyla Roksan Caglar, Gergely Csibra, Do Turkish indirect evidential sentences provide information but thwart generalization? Konverentsiettekanne Nijmegeni Radboudi Ülikoolis 9. jaanuaril 2014. 
arvestada, et türgi evidentsiaali tähendusruum ja kasutusreeglid on eesti omadest erinevad ning seetõttu võivad eesti ja türgi tulemused ka erineda.

Kasutatud katse on eesti evidentsiaalsuse omandamise uurimise plaanitud sarjas esimene ning sellega ei saa otsest vastust küsimusele, kuidas eesti lapsed evidentsiaalsuse markeriga edastatud teavet täpselt mõistavad. See annab ainult infot selle kohta, kas nad niimoodi esitatud teabele kuidagi eripäraselt (eri vanuses) reageerivad. Sarja järgmise katsega vaadeldakse seda, kas ja kuidas eesti nelja-, kuue- ja üheksa-aastased lapsed kaudses kõneviisis edastatud info allikat mõistavad. Seotud uuringutest (Argus jt ilmumas) selgub, et hoolimata evidentsiaali harvaesinevusest saavad lapsed aru, et evidentsiaal väljendab kaudsust. Kui näiteks katses kasutatud nukk teatas „Ema töö juures olevat punaste plikititega arvutimäng”, siis arvas $63 \%$ kuueaastastest lastest juba, et info arvutimängu kohta on kaudne.

\section{Evidentsiaalsuse omandamisest eri keeltes}

On teada, et kolmeaastased lapsed oskavad usaldada oma taju: mingi tegevuse otsene nägemine tekitab teadmise, et see on tõene (Zufferey 2010: 88), verbaalsele infole oskavad lapsed toetuda alles hiljem, nelja-viieaastaselt, ning verbaalne info paistab olevat keerukam tõestuse allikas kui vahetu visuaalne taju. Arusaam sellest, et info allikas võib olla ka vahendatud ehk info võib tulla kas järelduse või kuulujutuna, areneb Sandrine Zufferey sõnul välja kõige varem kuueaastaselt (Zufferey 2010: 88).

Umbes kolmeaastaselt on lastel omandatava keele grammatika põhituum enamasti omandatud. Katherine Nelson (1996) väidab, et kognitiivne ja keeleline areng on keeleomandamises põimunud ning et kõigepealt vormivad lapsed sellest, mida on konkreetsetes situatsioonides vahetult kogenud, nn sündmuste mentaalsed esitused (ingl representations). Seejärel kannavad lapsed sündmuse mentaalse esituse osad verbaalsesse vormi, et neid saaks suhtluses kasutada. Kui grammatika on omandatud, võimaldab see verbaalsete vormide teisendamist keelelisteks esitusteks (ingl linguistic representations) ning lapsed suudavad suhtluses ka teiste kaasvestlejate keelelisi üksusi tõlgendada ja sulatada sealt saadud elemente iseenda mentaalsetesse esitustesse. Samas ei pruugi lapsed eristada ise oma kogemuse kaudu omandatud esitusi neist, mis on omandatud kaudselt. Arengu järgmisel astmel on laps juba võimeline looma uusi mentaalseid esitusi ka teiste vestluskaaslaste keeleliste esituste põhjal. Erinevus eelmisest etapist 
seisneb selles, et need esitused võivad olla säilitatud pikaajalises mälus ja seega suudavad lapsed eristada neid esitusi, mis põhinevad nende enda kogemustel, neist, mis on omandatud kaudselt, ning mitte segi ajada nende teadmiste allikat. Selle tulemusena areneb välja nn metaesituste võime (ingl metarepresentational capacity), mis võimaldab eristada kogemustepõhiseid sündmuse esitusi kaudselt omandatud esitustest.

Evidentsiaalsuse omandamise kognitiivseid aspekte on näiteks uuritud korea ja türgi keeles (Papafragou jt 2007). Mõni eri keelte evidentsiaalsussüsteeme, keele ja taju üksteisest sõltuvat arengut käsitlev kirjutis on samuti juba ilmunud (nt Villiers jt 2009). On leitud, et keeltes, kus evidentsiaalsuse väljendamine on kohustuslik (nt türgi), omandatakse see varem (Aksu-Koç 1988; Choi 1995). Lisaks on teada, et kuigi lapsed õpivad evidentsiaalsuse markereid kasutama suhteliselt vara, võib nende markerite täielik mõistmine tekitada probleeme veel kuueaastastelgi (Zufferey 2010: 88). Igal juhul on teiste keelte omandamise andmetest teada, et evidentsiaalid omandatakse suhteliselt hilja (Aksu-Koç 1988: 25; Zufferey 2010: 88), vahel alles isegi üheksa-kümneaastaselt (Villiers jt 2009: 44). Eri tüüpi evidentsiaalid omandatakse ise vanuses: näiteks türgi järeldusliku evidentsiaali omandavad lapsed pooleteise-kahe aasta vanuses, nn hearsay ehk meie eesti kaudsele evidentsiaalile paremini vastava indirektaali alles kahe-kolme aasta vanuselt. Dan Slobin ja Ayhan AksuKoç väidavad, et türgi laste keelelises arengus kujuneb meie evidentsiaalile vastav evidentsiaal välja hiljem, umbes nelja aasta vanuses (Slobin, Aksu 1982; Aksu-Koç, Slobin 1986; Fitneva 2001). Aksu-Koç käsitleb evidentsiaalide all ka geneerikut -DIr ja märgib, et kahe-kolme aasta vanuses areneb välja ka selle markeri õige kasutamine (Aksu-Koç jt 2009). Geneerik on kõnealuses uurimuses paigutatud evidentsiaalide sekka, sest nii geneerikud kui ka muud türgi evidentsiaalid annavad informatsiooni info allika kohta, ainult et evidentsiaalide puhul on info allikas olemas ja geneerikutega edastatakse infot, millel üldse mingit allikat ei ole (vt geneerikute ja nende tüüpide kohta Carlson jt 1995).

Eesti keele evidentsiaalsuse omandamise kohta andmed puuduvad. Samas võib eelkirjeldatud keelte andmete põhjal oletada, et ka eesti keele evidentsiaalsuse omandavad lapsed pigem pärast kolmeaastaseks saamist. Pikiuuringu materjalidest (kõikidest eesti lastekeele alamkorpustest, mis on koondatud andmekogusse CHILDES) võib leida ainult kaks näidet vat-vormi kasutamise kohta. 
*EMA: päris maitsev jogurt paistab olevat.

(CHILDES, Vija; lindistus lapse vanusest 2;1.73)

*EMA: ta miskipärast rääkis, et sa olevat lubanud.

(CHILDES, Vija; lindistus lapse vanusest 3;0.25)

Pidama-verbiga evidentsiaalsust väljendavaid konstruktsioone kasutatakse samuti harva ja näiteid leiab alles 11 aastase lapsega lindistatud dialoogist.

*EMA: ega sa ei peagi päikest võtma ega ma ei mõtlegi et sa pead kuskil rätiku peal lamama ja päikest võtma sa jooksed ringi selle Jakobiga ja Gregoryga ja seal on teisi lapsi ka vist pidi olema. (Harley 11;11)

*LAPS: lõhkus arvuti ära sellest pidi tulema tulevane arvuti minul ja Gregoryl pealegi see oli väga hea arvuti. (Harley 11;11)

See, et evidentsiaalsust väljendavad vormid on harvad, on põhjendatav sellega, et keeleelementide sagedusel on mitu pragmaatilist ja kognitiivset piirangut. Pragmaatilistest piirangutest on oluline kahtlemata see, et tihti ei räägita asjadest, mille kohta on kuuldud mujalt; kui ka räägitakse, siis tõstetakse esile seda, et kuuldu mõtet täielikult ei jagata. Veelgi enam, lapsevanemal ei ole vajadust lapsele edastada infot, millesse ta ise päris kindlalt ei usu. Oma lapsega rääkimisel on kommunikatsiooni eesmärk jagada teadmisi eelkõige maailmas hakkama saamiseks, mitte näiteks edastada kuskilt kuuldud kahtlast infot, millest ise peetakse oluliseks end distantseerida. Kognitiivsest vaatepunktist võib arvata, et lapsevanem ei kasuta lapsega suheldes keelendeid, mida ta peab lapse arengu seisukohast mõttetuks. Lapsel ei ole kolmeaastaselt veel piisavalt kognitiivseid oskusi, et eristada enda ja teise inimese teadmisi, seetõttu on keeleliste katsete tegemisega parem alustada veidi hiljem. Lapse seisukohast on see, mida tema teab, teada ka teistele situatsioonis osalejatele ja kognitiivselt ei saada evidentsiaalist kui kaudsust väljendavast markerist lihtsalt aru.

Samuti on eesti keelele iseomane, et evidentsiaal on valikuline, st et sama tähendussisu saab väljendada ka ilma kaudse kõneviisi markerita (Ta rääkis, et sa oled lubanud / Sa olid lubanud, et ..). Nii puudub lastel tegelikult õige ettekujutus, millistel juhtudel evidentsiaali üldse kasutatakse, see aga erineb näiteks ettekujutusest mitmuse kasutuse kohta.

${ }^{3}$ Laste vanust 2;1.7 tuleks lugeda 2 aastat, 1 kuu ja 7 päeva. 
Eelöeldu põhjal võib arvata, et eksperimentaalse andmestiku kasutamine eesti evidentsiaalsuse omandamise ja mõistmise uurimiseks on ilmselt ainuvõimalik uurimismeetod, sest spontaanse kõne materjalist ei ole evidentsiaalsuse kohta andmeid lihtsalt leida.

\section{Meetod}

Uurimismeetodina on siinses uuringus kasutatud Butleri ja Markmani eeskujul avastamismängu (Butler, Markman 2012). Katse on olemuselt psühholingvistiline käitumisuuring, milles vaadeldakse teate vormi ja sisu mõistmist käitumise kaudu.

Katses tutvustatakse lastele uut eset. Kõigepealt öeldakse selle eseme nimetus ja seejärel tutvustatakse eraldi selle omadust. Seejärel ühendatakse uus ese ja omadus lause abil. Lastel lubatakse uue eseme teiste eksemplaridega mängida, ent neil puudub esemele omistatud omadus. Hiljem mõõdetakse digisalvestatud materjali põhjal, kuidas uusi esemeid ja nende omadusi mängus proovitakse.

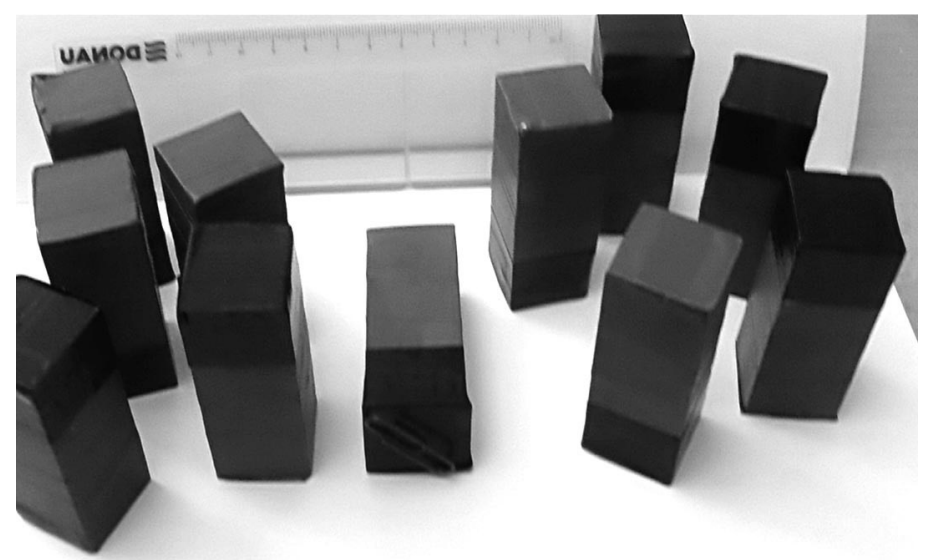

Joonis 1. Plikitid

Katse käigus oli lapsele tutvustatavaks uueks esemeks klotsiga sarnanev $5 \mathrm{~cm}$ pikkune ja 2,5 cm jämedune puust ja värvilise teibiga kaetud mänguasi (nn plikit, vt joonis 1). Eseme omadusi ehk seda, mis on magnetilisus, tutvustati külmkapimagnetite abil ning nii sai laps ka ise soovi korral 
katsetades aru, mida tähendab magnet ja magnetilisus. Kõik plikitid olid välimuselt identsed. Seejärel anti lapsele ühe demonstreeritava plikiti omaduste kohta sõnalist teavet, aga ei näidatud visuaalselt, kas demonstreeritaval plikitil need omadused ka tõesti on. Katses kasutati teabe edastamiseks kaht viisi ehk tingimust, mis varieerusid keelelise vormi poolest.

Tingimus 1 (algtingimus):

Plikit on magnet. $(n=42)^{4}$

Tingimus 2 (evidentsiaal):

Plikit olevat magnet. $(n=43)$

Eesmärk oli teada saada, kas ja kuidas kasutavad lapsed klotsidega mängimisel klotside kohta varem saadud teavet ja kas evidentsiaaliga esitatud laused tekitavad lapses uute mänguasjade vastu rohkem huvi või hoopis pärsivad seda. Mängimine filmiti. Tulemused digisalvestati andmetöötluse tarbeks. Salvestisi kasutati mängutegevuse osade mõõtmiseks. ${ }^{5}$ Katse tehti läbi kokku 85 lapsega, kelle vanus oli neli-kuus aastat. Kuna oluline oli ka, kas meetod on usaldusväärne ja toimib, toimusid proovikatsed. Üks katse toimus visuaalsel moel, kus tingimus oli sõnaliselt väljendatud: Plikit on magnet, millele lisandus visuaalne demonstratsioon magnetilise plikitiga $(\mathrm{n}=10) .{ }^{6}$ Sõnalise (täpsemalt: leksikaalse) ja üldistava väljenduse mõju uurimiseks tehti katse läbi ka geneerilise tingimusega $(n=25){ }^{7}$ Tulemuste osas arutletakse, kuivõrd usaldusväärne on katse, et vanusegruppides ilmnevaid erinevusi uurida. Siinses artiklis ei käsitleta pikemalt kahe lisatingimusega seotud tulemusi, seda nii teoreetilise ainese mahukuse kui ka piisavateks järeldusteks vajaminevate katsete ebapiisavuse tõttu.

$4 n$ märgib katsete arvu.

5 Katse tegijad olid Airi Kapanen, Andra Kütt, Sirli Parm ja Kadri Suurmäe. Katse tingimused jaotati katsetajate vahel proportsionaalselt. Katsed tehti ajavahemikus 1. maist 2013 kuni 1. aprillini 2014 Tallinna lasteaedades Karikakar, Kiikhobu, Kullerkupu, Mikumanni ning Männi ja Pirita-Kose lasteaias; Saku lasteaedades Päikesekild ja Terake, Värska lasteaias ning Viljandi lasteaias Mesimumm. Lapse isikuandmed ja salvestised hoitakse eraldi failides. Digimaterjali kasutatakse rangelt vaid mänguosade mõõtmiseks ja filmid hävitatakse, kui uurimus on valmis.

6 Visuaalse tingimuse lisasime, et kontrollida katses esitatud info modaalsuse toimet mängule. Kui õppida on vaja esemete, näiteks tööriistade funktsioone, siis oletasime, et visuaalne teave võib sõnalisest olulisemaks osutuda, samuti omandatakse infot visuaalsel teel teistsuguste kognitiivsete protsesside kaudu.

7 Geneerilise tingimuse lisasime, et kontrollida katses esitatud info leksikaalse vormi toimet üldistamisele. Kui õppida on vaja kiiresti, siis oletasime, et geneerilisena esitatud info aitab lastel kiiremini orienteeruda, millist infot tasub üldistada. 


\subsection{Katse protseduur}

Katse koosnes kolmest faasist: MIS ONMAGNET-UUS SÕNA-MÄNG. Kõigepealt tutvustati lapsele magneteid, st erinevaid magnetiliste omadustega materjale ja esemeid. Uuringu tegija pani lauale viis külmkapimagnetit ja väikese karbi kirjaklambritega ning ütles: „Kuigi need asjad on kõik erinevad, on nad kõik magnetid. See tähendab, et nad saab kodus näiteks külmkapi külge panna." Seejärel võttis katse tegija väikesest karbist osa kirjaklambreid välja ja pani lauale: „Või saab nende külge kirjaklambreid tõmmata." Seejärel võttis ta ühe magneti ja tõmbas veidi kirjaklambreid selle külge. Siis sai ka laps magneteid proovida: „Nüüd saab magneteid proovida, kui sina ka soovid neid proovida.” Seega sai laps õppida selgeks, mida tähendab magnet ja mida see teeb. Seejärel sai laps katse tegijalt uut teavet ühe täiesti uue mänguasja kohta, talle öeldi, et selle nimi on ,,plikit”.

Uuringu tegija tõi lauale kaks karbikest, mõlemas viis eset, millest üks oli plikit ja ülejäänud nn segajad, st muud esemed. Katse toimus järgmise stsenaariumi järgi.

- Katse tegija tõstis plikiti ühest karbikesest välja ja ütles: „See on plikit."

- Kui laps ei näinud, pani katse tegija karbi ära ja kordas tegevust teise karbikesega.

- Siis võttis katse tegija uuesti esimese karbikese viie esemega, öeldes: „Vaata karpi. Kas oskad öelda, milline neist on plikit?”.

- Seejärel kordas katse tegija plikiti leidmise katset teise karbikesega.

Niisiis paluti lapsel kaks korda valida nelja muu väikesemõõdulise värvilise eseme seast (nt külmkapimagnetid) nn plikit, et kindlaks teha, kas laps on eseme nimetuse edukalt selgeks õppinud.

Seejärel andis katse tegija plikiti omaduste kohta teavet, kasutades üht kahest eeltoodud tingimusest. Kui see tehtud, siis hakkas katse tegija muid mänguasju koristama ja ütles: „Ma pean nüüd natuke koristama, sina mängi plikititega, kui tahad." Katse tegija asetas lauale 10 plikitit. Välimuselt sarnanesid need plikitid varem näidatud plikititega, aga väitest hoolimata ei tekitanud nad mingit magnetvälja. Katse tegija pani plikitid lapse ette kirjaklambrite juurde lauale ja ütles: „Siin on mõned plikitid. Mängi nendega, kui soovid. Ma seni koristan siin.” Lapsel lasti 60 sekundit plikititega mängida. 


\subsection{Andmete kodeerimine}

Katseid kodeeriti ainult nende 60 sekundiliste ajalõikude jooksul, mil lapsele anti võimalus plikititega mängida. Kodeerimisaja jooksul vaadeldi laste mängu kolme näitaja põhjal: aeg, mis lapsel kulus plikitite magnetiliste omaduste katsetamiseks; konkreetsete magnetiliste omaduste katsetamiseks tehtud liigutuste ja proovitud plikitite arv. Kui laps ütles pärast mängimist, et plikitid ei töötanud korralikult, anti talle üks õige plikit ning vaadati, kas ja mitu korda laps selle magnetilisi omadusi proovib.

Plikitite magnetiliste omaduste proovimisena arvestati ainult neid kordi, mil laps üritas näiteks kirjaklambrit plikiti külge tõmmata või kaht plikitit omavahel horisontaalselt kokku panna. Neid kordi, kui laps kasutas plikiteid ainult ehitamiseks ehk ladus näiteks plikitid üksteise otsa torniks, arvesse ei võetud. Proovitud plikititena loendati neid mänguklotse, mille külge laps üritas kirjaklambreid või teisi plikiteid tõmmata, mille peale ta asetas klambreid või mida ta üritas teise plikitiga ühendada. Mõnikord, kui oli raske aru saada, kas laps katsetab plikiti magnetilisi omadusi või pigem lihtsalt mängib, aitas ka lapse vastuse kuulamine selle kohta, mis ta plikitite kohta teada sai. Katse loeti õnnestunuks, kui tegemist oli ükskeelse lapsega, lapse vanus oli katseks sobiv ja katse tegemisel oli stsenaariumist, näiteks mõõtmisajast, täpselt kinni peetud.

Katse tulemusi mõõtis kaks inimest ja töö toimus teineteisest sõltumatult. Hiljem tulemusi võrreldi. Kahel kodeerijal oli eri tõlgendusi vähe: 26 korral, kui kodeerijate tulemused erinesid, oli tegemist ühe sekundi piiresse jääva eriarvamusega mängimise alguse aja arvestamisel. Kõik sellised kohad vaatasid kodeerijad filmil koos üle ning tegid algusaja kohta ühise otsuse. Plikitite ja katsetamiste arvu erimeelsused ei mõjutanud.

\section{Katse tulemused}

Järgnevalt on tulemused esitatud kolme näitaja alusel: mõõdetud on katsetamiste arvu (ehk seda, mitu korda laps plikitite magnetilisi omadusi proovis), mängimisel kasutatud plikitite arvu ja mängu kestust sekundites eraldi kahe katsetingimuse ehk kahte tüüpi keelelise (laiemalt: nelja tüüpi keelelis-visuaalse) sisendi kaupa. Tulemuste kirjeldused hõlmavad nii keeleliste kui ka keelelis-visuaalsete tingimustega tehtud katsete mõõtmiste tulemusi, ent täpsemad kirjeldused ning arutelu puudutab vaid algtingimust ja evidentsiaalset tingimust. 
Esimene hüpotees oli, et lapsed katsetavad rohkem ja suuremal arvul plikiteid ning mängivad kauem neutraalse ehk algtingimuse puhul, sest evidentsiaaliga esitatud teabesse peaksid lapsed suhtuma kui millessegi, mis on vahendatud ega pruugi seega tõsi olla ning mis võib kehtida vaid ühe plikiti kohta. Teise hüpoteesina oletasime, et vanuse kasvades laste reageerimine eri viisil esitatud teabele muutub. Seepärast on järgnev analüüs esitatud nelja-aastaste ja kuueaastaste laste tulemusi võrreldes.

Mõlema vanusegrupi kohta võib öelda, et algtingimuse ehk indikatiivis lause puhul katsetatakse plikitite omadusi vähem kui evidentsiaalidega lause puhul. Vahe ei ole siinjuures statistiliselt oluline $(=0,78)$-vanemad lapsed olid üldse aktiivsemad. Oluline on pigem see, et nelja-aastaste laste puhul oli aga vahe tingimuseti olulisem kui kuueaastaste puhul. Võib väita, et nelja-aastased lapsed katsetavad plikiti omadusi siis, kui nende omaduste kohta antakse teave indikatiivis lausega, selgelt vähem, kui siis, kui see teave antakse evidentsiaaliga (vahe statistiline olulisus oli $0,016)$. Kui algtingimuse ja evidentsiaalse tingimuse vaheline erinevus on LCD post-hoc-testi järgi oluline $(0,016)$, siis samade tingimuste erinevust kuueaastaste laste puhul märgata ei ole (erinevuse olulisus oli vaid 0,964 ).

Selle näitaja küllalt suurest standardhälbest võib näha, et lapsed käitusid grupi sees erinevalt, kõige rohkem erinesid tulemused evidentsiaalse tingimuse puhul.

Tabel 1. Katsetamiste arv, nelja-aastased lapsed

\begin{tabular}{|l|c|c|c|}
\hline \multicolumn{1}{|c|}{ Tingimus } & $\begin{array}{c}\text { Keskmine } \\
\text { katsetamiste arv }\end{array}$ & Laste arv & Standardhälve \\
\hline Algtingimus & 2,3333 & 27 & 3,07596 \\
\hline Evidentsiaalid & 6,6190 & 21 & 9,16229 \\
\hline Kokku/keskmine & 4,2083 & 48 & 6,75076 \\
\hline
\end{tabular}

Tabel 2. Katsetamiste arv, kuueaastased lapsed

\begin{tabular}{|l|c|c|c|}
\hline \multicolumn{1}{|c|}{ Tingimus } & $\begin{array}{c}\text { Keskmine } \\
\text { katsetamiste arv }\end{array}$ & Laste arv & Standardhälve \\
\hline Algtingimus & 7,0000 & 15 & 9,00793 \\
\hline Evidentsiaalid & 7,1364 & 22 & 9,03061 \\
\hline Kokku/keskmine & 7,0811 & 37 & 8,89562 \\
\hline
\end{tabular}


Tabelist 2 nähtub, et katsetatud plikiteid arvestades ei erine kuueaastaste laste tulemused alg- ja evidentsiaalse tingimuse poolest kuigivõrd (vahe olulisus oli 0,985$)$.

Tabelites 3 ja 4 on esitatud magnetiliste omaduste katsetamisteks kasutatud plikitite arv eri tingimuste kaupa.

Tabel 3. Plikitite arv, nelja-aastased lapsed

\begin{tabular}{|l|c|c|c|}
\hline \multicolumn{1}{|c|}{ Tingimus } & $\begin{array}{c}\text { Keskmine } \\
\text { plikitite arv }\end{array}$ & Laste arv & Standardhälve \\
\hline Algtingimus & 1,3704 & 27 & 1,75736 \\
\hline Evidentsiaalid & 2,0952 & 21 & 2,16575 \\
\hline Kokku/keskmine & 1,6875 & 48 & 1,95868 \\
\hline
\end{tabular}

Tabel 4. Plikitite arv, kuueaastased lapsed

\begin{tabular}{|l|c|c|c|}
\hline \multicolumn{1}{|c|}{ Tingimus } & $\begin{array}{c}\text { Keskmine } \\
\text { plikitite arv }\end{array}$ & Laste arv & Standardhälve \\
\hline Algtingimus & 2,4667 & 15 & 2,26358 \\
\hline Evidentsiaalid & 2,4545 & 22 & 1,59545 \\
\hline Kokku/keskmine & 2,4595 & 37 & 1,86480 \\
\hline
\end{tabular}

Magnetiliste omaduste katsetamiseks kasutatud plikitite arv ei erine oluliselt ei laste vanust ega kasutatud tingimusi arvestades.

Tabelites 5 ja 6 on esitatud plikitite magnetiliste omaduste katsetamisteks kulunud aeg (mängu kestus) sekundites eri tingimuste kaupa.

Tabel 5. Mängu kestus, nelja-aastased lapsed

\begin{tabular}{|l|c|c|c|}
\hline Tingimus & Keskmine & Laste arv & Standardhälve \\
\hline Algtingimus & 12,5556 & 27 & 19,90619 \\
\hline Evidentsiaalid & 17,9048 & 21 & 20,93539 \\
\hline Kokku/keskmine & 14,8958 & 48 & 20,32003 \\
\hline
\end{tabular}

Tabel 6. Mängu kestus, kuueaastased lapsed

\begin{tabular}{|l|c|c|c|}
\hline Tingimus & Keskmine & Laste arv & Standardhälve \\
\hline Algtingimus & 21,2000 & 15 & 23,66190 \\
\hline Evidentsiaalid & 19,2273 & 22 & 19,19060 \\
\hline Kokku/keskmine & 20,0270 & 37 & 20,82131 \\
\hline
\end{tabular}


Magnetiliste omaduste katsetamiseks kulunud aeg ei erine oluliselt ea- ja tingimusegruppides.

Kaasates proovikatsetest saadud andmed, ilmneb, et vanus mängib mängu kestuse, katsetamiste ja plikitite arvu puhul (vt tabel 7) olulist rolli. Suuremad lapsed mängivad oluliselt rohkem (kestuse vahe olulisus ehk $\mathrm{p}=0,005$ ), katsetavad rohkem kordi (katsetamiste vahe olulisus ehk $\mathrm{p}=0,002$ ) ja suuremal hulgal plikiteid (vahe olulisus ehk $\mathrm{p}=0,002$ ).

Tabel 7. Vanusegruppide tulemuste võrdlus kolme tingimuse põhjal

\begin{tabular}{|l|l|c|c|c|}
\hline \multicolumn{2}{|c|}{ Vanus } & $\begin{array}{c}\text { Mängu } \\
\text { kestus }\end{array}$ & $\begin{array}{c}\text { Katsetamiste } \\
\text { arv }\end{array}$ & Plikitite arv \\
\hline \multirow{4}{*}{ Nelja-aastased } & Keskmine & 15,6324 & 4,1912 & 1,7500 \\
\cline { 2 - 5 } & $\mathrm{N}$ & 68 & 68 & 68 \\
\cline { 2 - 5 } & Standardhälve & 19,92291 & 6,16504 & 1,81515 \\
\hline \multirow{4}{*}{ Kuueaastased } & Keskmine & 27,0385 & 8,6923 & 2,8846 \\
\cline { 2 - 5 } & $\mathrm{N}$ & 52 & 52 & 52 \\
\cline { 2 - 5 } & Standardhälve & 23,20832 & 9,18767 & 2,18420 \\
\hline \multirow{3}{*}{$\begin{array}{l}\text { Kokku/ } \\
\text { keskmine }\end{array}$} & Keskmine & 20,5750 & 6,1417 & 2,2417 \\
\cline { 2 - 5 } & $\mathrm{N}$ & 120 & 120 & 120 \\
\cline { 2 - 5 } & Standardhälve & 22,05747 & 7,91159 & 2,05388 \\
\hline
\end{tabular}

Seega võib arvata, et eri näitajatel on üldplaanis vanusegrupiti selge efekt: nooremad lapsed mängivad oluliselt vähem intensiivselt igas mõõtmes. Evidentsiaalide ja algtingimuse võrdlusel mingeid tugevaid erinevusi plikitite arvus ja mängu kestuses aga ei esinenud. Küll aga osutus katsetamiste arv evidentsiaalse ja algtingimuse puhul kõnekaks näitajaks.

\section{Arutelu}

Katsealustes gruppides on kognitiivse arengu seisukohast juba võimalik teateid mõtestada vahendatud infona. Seega peaks olema ka võimalik evidentsiaalidest aru saada. Kui teave on vahendatud, siis saab oletada, et see on ka vähem usaldusväärne. Selle eelduse kohaselt ei sobi teave üldistamiseks.

Seevastu saadud katseandmete analüüs näitas, et kui info antakse evidentsiaali kujul, siis võrreldes algtingimusega on nelja-aastased lapsed 
visamad plikitite omadusi katsetama, seda näitas katsetamiste arv. Kui väide esitatakse evidentsiaaliga, siis ajendab see lapsi intensiivsemalt mängima ja välja uurima, kas öeldu peab paika, kui mängu käigus selgub, et väide ei pea katseesemete teiste eksemplaride puhul paika. Selle asemel et evidentsiaali tõlgendada hoiatusena, et teave ei tule ütlejalt, võivad nelja-aastased lapsed hoopis järeldada, et kui täiskasvanu juba seda infot, mida ta on mujalt teada saanud, peab tarvilikuks edastada, siis peab see olema tavalisest olulisem. Veel tõenäolisem on aga, et kui tegemist on lapse jaoks täiesti uue morfeemiga, siis võib see lapses just huvi tekitada kui miski, mis on uus huvitav grammatika (kuigi ilmselt arusaamatu) ja justkui keeleavastamine. Selle kasuks räägib fakt, et kuueaastaste laste tulemused alg- ja evidentsiaalse tingimuse puhul oluliselt ei erinenud. Ka pikiuuringutega on kindlaks tehtud, et keeltes, kus on rikkam muutemorfoloogia, pööravad lapsed morfoloogiale varem tähelepanu kui neis keeltes, kus morfoloogiat on vähem (Laaha, Gillis 2007).

Kuigi erinevus kahe tingimuse vahel on kuueaastastel lastel juba kadunud, ei üldista kuueaastasedki evidentsiaaliga antud info põhjal algtingimusest vähem. Sellel võib olla vähemalt kaks põhjust. Üks neist on pragmaatiline - situatsioon ei võimalda info kaudsusest järeldada selle ebausaldusväärsust. Teine põhjus on võimalus, et kuueaastased ei saa evidentsiaalide tähendusest päris nii aru nagu täiskasvanud keelekasutajad.

\section{Kokkuvõte}

Eesti evidentsiaalsuse mõistmise arenemise algetapi kohta võime oletada, et uus ja lastele suure tõenäosusega tundmatu grammatiline element tekitab rohkem huvi kui tavapärasem ja tuttavam grammatika, ent see efekt kaob lapse ja tema keele arengu jooksul. Edasises uuringus tuleks keskenduda kontrollkatsetele ja vanematele eagruppidele. Tasub mõelda ka sellele, miks lapsed evidentsiaalidega väljendatud infot just sellisel moel tõlgendavad ja mida saadud andmed teiste keeltega võrreldes eesti keele evidentsiaalide kohta ütlevad. 


\section{Kirjandus}

Aikhenvald, Alexandra Y. 2004. Evidentiality. Oxford: Oxford University Press. Aksu-Koç, Ayhan 1988. The Acquisition of Aspect and Modality. The Case of Past Reference in Turkish. (= Cambridge Studies in Linguistics. Supplementary Volume.) Cambridge: Cambridge University Press. http://dx.doi. org/10.1017/CBO9780511554353.

Aksu-Koç, Ayhan, Dan Slobin 1986. A psychological account of the development and use of evidentials in turkish. - Evidentiality: the Linguistic Coding of Epistemology. Ed. Wallace Chafe, Johanna Nichols. (= Advances in Discourse Processes 20.) Norwood, New Jersey, 159-167.

Aksu-Koç jt 2009 = Ayhan Aksu-Koç, Hale Ögel-Balaban, I. Ercan Alp. Evidentials and source knowledge in Turkish. - New Directions in Child and Adolescent Development 125, 13-28. http://dx.doi.org/10.1002/cd.247.

Argus jt ilmumas $=$ Reili Argus, Kadri Suurmäe, Andra Kütt, Anne Tamm. Eesti keele evidentsiaalsuse omandamisest: mõistmiskatse tulemused. - Tallinna ülikooli eesti keele ja kultuuri instituudi toimetised 16. Tallinna Ülikool.

Butler, Lucas P., Ellen M. Markman 2012. Preschoolers use intentional and pedagogical cues to guide inductive inferences and exploration. Child Development 83, 1416-1428. http://dx.doi.org/10.1111/j.14678624.2012.01775.x.

Carlson, Gregory N., Francis Jeffry Pelletier 1995. The Generic Book. Chicago: University of Chicago Press.

Choi, Soonja 1995. The development of epistemic sentence-ending modal forms and functions in Korean children. - Modality in Grammar and Discourse. Ed. Joan Bybee, Susanne Fleischman. (= Typological Studies in Language 32.) Amsterdam: John Benjamins Publishing Company, 165-204.

Erelt, Mati 2013. Eesti keele lauseõpetus. Sissejuhatus. Öeldis. (= Tartu Ülikooli eesti keele osakonna preprindid 4.) Tartu.

Fitneva, Stanka 2001. Epistemic marking and reliability judgments: evidence from Bulgarian. - Journal of Pragmatics 33 (3), 401-420.

Giardini jt ilmumas $=$ Francesca Giardini, Stanka A. Fitneva, Anne Tamm. Source manipulation and strategic information giving: an experimental study on epistemic markers in competitive and cooperative contexts.

Hendriks, Petra, Helen de Hoop 2001. Optimality theoretic semantics. Linguistics and Philosophy 24, 1-32.

Kehayov, Petar 2004. Eesti keele evidentsiaalsussüsteem mõne teise keele taustal. Morfosüntaks ja distributsioon. - Keel ja Kirjandus 11, 812-829.

Kolk jt $2010=$ Anneli Kolk, Triin Raud, Mariliis Kaldoja. Sotsiaalsete oskuste ja n-ö mõtete lugemise võime areng lastel nooremas koolieas. - Eesti Arst 89 (11), 725-732. 
Kütt jt 2014 = Andra Kütt, Anne Tamm, Reili Argus. Evidentsiaale kasutame strateegilise suhtlusvahendina. - Oma Keel 1, 51-58.

Laaha, Sabine, Steven Gillis (ed.) 2007. Typological Perspectives on the Acquisition of Noun and Verb Morphology. (= Antwerp Papers in Linguistics 112.) Antwerp: University of Antwerp.

Nelson, Katherine 1996. Language in Cognitive Development. The Emergence of the Mediated Mind. Cambridge: Cambridge University Press. http:// dx.doi.org/10.1017/CBO9781139174619.

Papafragou jt 2007 = Anna Papafragou, Peggy Li, Youngo Choi, Chung-hye Han. Evidentiality in language and cognition. - Cognition 103, 253-299. http://dx.doi.org/10.1016/j.cognition.2006.04.001.

Slobin, Dan, Ayhan A. Aksu 1982. Tense, aspect, and modality in the use of the Turkish evidential. - Tense-Aspect: Between Semantics and Pragmatics. Ed. Paul J. Hopper. Amsterdam, Philadephia: John Benjamins Publishing Company, 185-200. http://dx.doi.org/10.1075/tsl.1.13slo.

Zufferey, Sandrine 2010. Lexical Pragmatics and Theory of Mind. The Acquisition of Connectives. (= Pragmatics \& Beyond New Series 201.) Amsterdam: John Benjamins Publishing Company. http://dx.doi.org/10.1075/ pbns.201.

Tamm, Anne 2009. The Estonian partitive evidential. Some notes on the semantic parallels between the aspect and evidential categories. - Papers from TAM TAM. Cross-linguistic Semantics of Tense, Aspect, and Modality. Ed. Lotte Hogeweg, Helen de Hoop, Andrei Malchukov. (= Linguistics Today 148.) Amsterdam: John Benjamins Publishing Company, 365-401.

Villiers jt 2009 = Jill de Villiers, Jay Garfield, Harper Gernet-Girard, Tom Roeper, Margaret Speas. Evidentials in Tibetan: acquisition, semantics, and cognitive development. - Evidentiality: A Window into Language and Cognitive Development. Ed. Stanka A. Fitneva, Tomoko Matsui. (= New Directions for Child and Adolescent Development 125.) San Francisco: Jossey-Bass, 29-47. 


\title{
Evidential sentences guiding Estonian preschoolers' exploration of novel objects and their properties
}

\author{
Anne Tamm, Reili Argus, \\ Kadri Suurmäe
}

The article focuses on the effect of the Estonian evidential on preschoolers' exploratory play, contrasting it with the effect of normal indicative sentences. The methods involved a behavioral experiment, where 4 and 6-year-old children were presented with one single instance of a new object ("a blicket"). A property was demonstrated ("being a magnet") with other objects. The experimenter then ascribed the magnetic property to the demonstrated novel object in two different ways. In Condition 1, the magnetic property was ascribed to the object by means of a neutral, indicative statement. Condition 2 used an evidential sentence. Inert, non-magnetic blickets and paperclips were placed in front of the children, who were then asked if they wanted to play with blickets. The duration of their play, the number of attempts to test the properties of the object, and the number of blickets were measured on the basis of the videotaped material. We found that the evidential sentences increased the number of attempts to explore the properties among 4-year-olds, but not among 6-year-olds. The increased play that occurred with evidentials may tentatively be attributed to the novelty of the grammar for the children and their expectations of its effect.

Keywords: evidentiality, acquisition of Estonian grammar, caregiver language, experimental methods 
Anne Tamm

kognitiivteaduste osakond

Kesk-Euroopa Ülikool (Central European University, CEU)

Hattyú utca 14

1015 Budapest

TammA@ceu.hu

nederlandistika osakond

humanitaarteaduskond

Gáspár Károli Kalvinistlik Ülikool (Károli Gáspár Református Egyetem, KRE)

Reviczky utca 4

1088 Budapest

tamm.anne@kre.hu

Reili Argus

eesti keele ja kultuuri instituut

Tallinna Ülikool

Narva mnt 25

10120 Tallinn

reili.argus@tlu.ee

Kadri Suurmäe

eesti keele ja kultuuri instituut

Tallinna Ülikool

Narva mnt 25

10120 Tallinn

kadri.suurmae@gmail.com 